\title{
THE RELATIONSHIP BETWEEN THE CLEARANCE AND THE PLASMA CONCENTRATION OF INULIN IN NORMAL MAN
}

\author{
By THOMAS J. KENNEDY, JR., AND JACK KLEH WITH THE TECHNICAL ASSISTANCE OF \\ ALMA B. BARTOL AND HENRY C. DICKERSON
}

(From the Section on Kidney and Electrolyte Metabolism, National Heart Institute, National In-
stitutes of Health, Public Health Service, Federal Security Agency, Bethesda, Md.)

(Submitted for publication September 25, 1952; accepted October 31, 1952)

\section{INTRODUCTION}

Shannon and Smith (1) found that in normal man, the rate of excretion of inulin was directly proportional to its concentration in plasma when the latter varied from 50 to $400 \mathrm{mg}$. per cent. Later Miller, Alving, and Rubin (2) extended these observations to plasma concentrations of inulin between 3 and $96 \mathrm{mg}$. per cent and reached similar conclusions. Both groups considered that this constituted important evidence that inulin clearance measured the rate of glomerular filtration. Recently, Ferguson, Olbrich, Robson, and Stewart (3) presented data showing that the rate of excretion of inulin was not directly proportional to its concentration in plasma, and that the clearance of inulin was dependent upon the concentration of this substance in plasma.

In view of the significance generally attached to the clearance of inulin in renal physiological studies and in view of the critical importance of precise estimation of glomerular filtration rate, it was decided to reinvestigate this problem.

\section{MATERIALS, METHODS AND CALCULATIONS}

One male and thirteen female subjects were selected for the study from the outpatient population of the George Washington University Hospital. None showed any evidence of cardiovascular renal disease on the basis of history, physical or laboratory examination. The group was predominately female because of the greater ease with which this type of study can be performed in women.

Clearance measurements were made in the postabsorptive state. Water was offered to the subjects to drink at the rate of about $250 \mathrm{ml}$. every 30 minutes, but was not forced if discomfort or nausea appeared. Preliminary blood and urine samples were collected for the estimation of blanks. Each experiment consisted of 3 groups of clearance periods, for each of which the plasma concentration of inulin was established and maintained at a constant value by appropriate priming and sustaining infusions. The constant levels sought were 5, 50, and $175 \mathrm{mg}$. per cent, respectively. Thirty minutes after the start of each infusion, three clearance periods were ob- tained. Periods varied from 10 to 20 minutes, depending on the urine flow. Urine was collected from an indwelling multi-eyed, soft rubber catheter, and each collection was terminated by washing twice with $20 \mathrm{ml}$. of distilled water followed by insufflation and re-expression of air. Blood was collected at the midpoint of each period from an indwelling femoral arterial needle and received into oiled syringes to which 2 drops of heparin solution had been added.

Inulin was measured in zinc filtrates of plasma and urine by a modification of the method of Harrison (4) after preliminary exposure to yeast. When the plasma concentration of inulin was less than $10 \mathrm{mg}$. per cent, the following procedure was used. Two ml. of plasma or urine were placed in a test tube to which $0.5 \mathrm{ml}$. of water and $0.5 \mathrm{ml}$. of a 40 per cent yeast suspension were added. Recovery experiments were made simultaneously in which $2 \mathrm{ml}$. of blank plasma, $0.5 \mathrm{ml}$. of an inulin standard and $0.5 \mathrm{ml}$. of yeast suspension were used. Fermentation was allowed to proceed for 20 minutes, following which the tubes were centrifuged and $2 \mathrm{ml}$. of the supernatant were removed. The latter was added to $5 \mathrm{ml}$. of a 4 per cent solution of zinc sulfate in $\mathrm{N} / 10 \mathrm{H}_{2} \mathrm{SO}_{4}$ and the protein was precipitated by the addition of $2 \mathrm{ml}$. of $0.75 \mathrm{~N} \mathrm{NaOH}$. From this point forward, the procedure followed that employed at high levels of inulin. In all analytical runs, recoveries were included. These averaged 98.6 per cent $(\sigma=2 \%)$ over a range of from 5 to $40 \mathrm{mg}$. per cent of inulin. Blank plasma from various patients contained from 0.15 to $1.15 \mathrm{mg}$. per cent of inulinoid chromogen, averaging $0.55 \mathrm{mg}$. per cent. At plasma concentrations of inulin between 3 and $10 \mathrm{mg}$. per cent the color attributable to blank averaged 8 per cent of the total color and in only 2 of the 14 subjects did it constitute more than 10 per cent of the total color during the clearance periods at low concentrations of inulin. The inulinoid chromogen in blank urine was equivalent to between 0.00 and 0.2 $\mathrm{mg} . / \mathrm{min}$. in the seven subjects examined and constituted between 0.0 and 3.1 per cent of the total color (average $1.2 \%$ ) when the rate of inulin excretion was low.

Clearance was calculated by dividing the average minute rate of excretion by the midperiod plasma concentration of inulin. No correction for delay time was applied.

The data were analyzed in two ways: By relating the rate of excretion to the plasma concentration of inulin and by examining the clearance of inulin as a function of its concentration in the plasma. In such an analysis it is 
necessary to consider the sources and magnitude of the errors involved. These are of two types: 1 ) The errors of the chemical estimations of the concentrations in plasma and urine, and 2) that attributable to variable emptying of the bladder, variable residual urine in dead space, and possibly to true variation in the excretion of inulin. The first type of error is, in practice, negligible with respect to the very considerable error in the collection of the urine. Further consideration also indicates that the absolute magnitude of the error is directly proportional to the absolute value of the measured quantity. Since all the chemical determinations are performed on final solutions containing approximately equal concentrations of inulin, the relative errors are approximately constant and are magnified by the preliminary dilutions to which the samples have been subjected. The absolute error is therefore proportional to the original concentration. A similar consideration applies to the error in the rate of excretion of inulin since a given fraction of the urine in any one period will contain more inulin when the rate of excretion is high than when the rate of excretion is low.

In the calculation of the regression of rate of excretion on plasma concentration, it is assumed that the error in the determination of the plasma concentration is negligible with respect to that involved in the determination of the rate of excretion; this assumption is apparently warranted. However, in the usual solution by the method of least squares it is assumed that the absolute variability does not change systematically over the range to which the data apply. This is obviously not the case in the present situation. In such an analysis of these data which cover up to a 40-fold range of UV and $P$, far too much weight is given to the values at high plasma concentration, since the deviations of the points at low plasma concentration from the regression line are small in any case. Furthermore, the error in the estimation of the intercept is exaggerated to an even greater extent and makes a significant departure of the intercept from zero (the hypothesis to be tested) very difficult to detect.

To overcome this distortion, the standard statistical procedure was applied by weighting each value by the inverse of its estimated variance. In this case, the variance is estimated to be proportional to the square of the absolute value. The procedure used was as follows: A line relating $U V$ to $P$ in each experiment was calculated by the method of least squares using the observed values of $U V$ and $P$ for each period. The values of the intercept on the UV axis and the standard error of the value of the intercept were also calculated. These are presented in the left-hand columns of Table III. The line thus calculated was used for the determination of weighting coefficients to be applied to the data in a further calculation. Values of UV on the line were determined corresponding to the several values of observed P. A

TABLE I

Inulin clearance at several plasma concentrations of inulin in two normal subjects

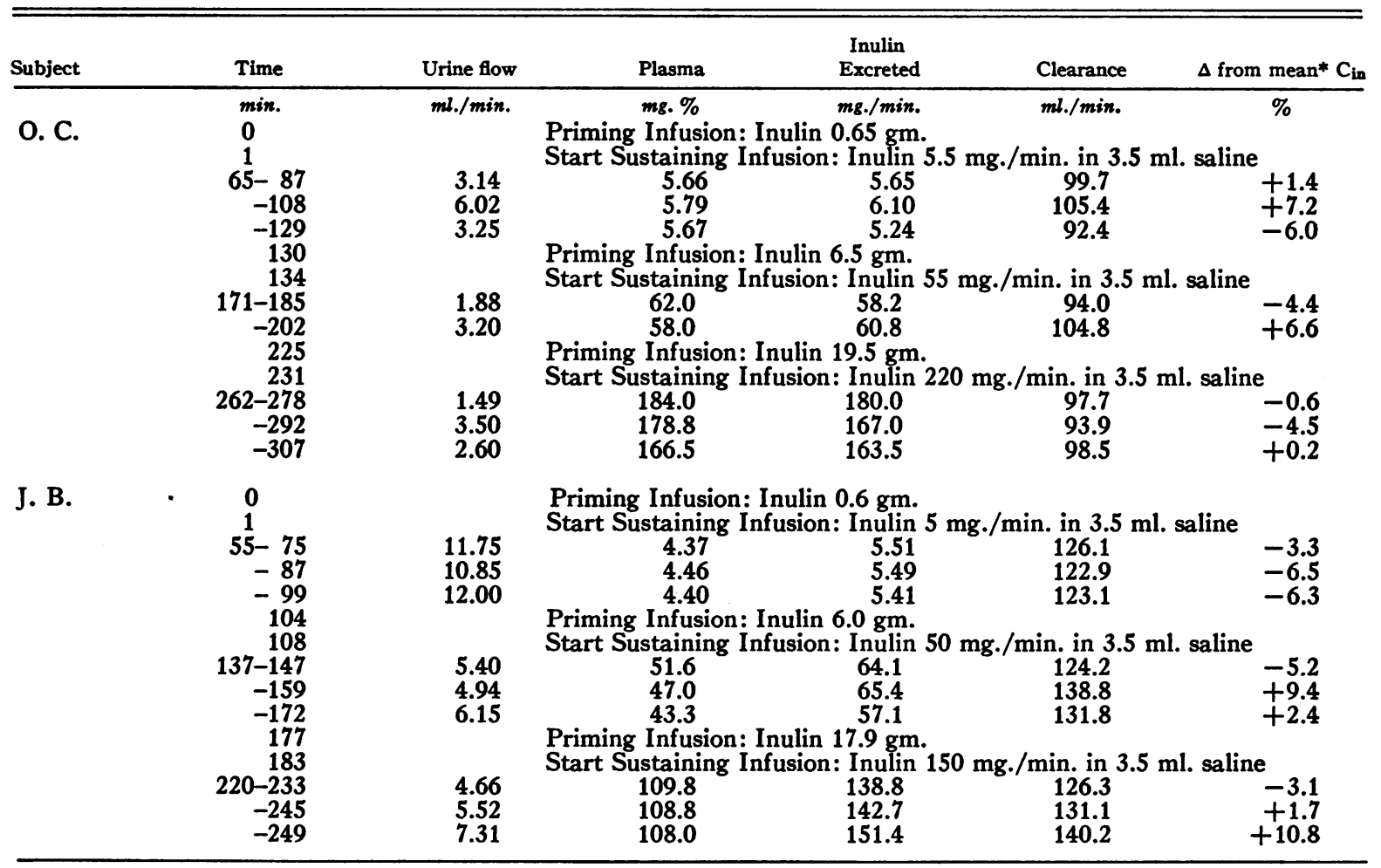

* Mean of the 9 periods in each experiment. 
weighting coefficient for each value of $U V$ and $P$ was calculated using the reciprocal of the square of the value of UV lying upon the line. The observed values of UV and $P$ were then weighted with these coefficients and the least square solution was repeated. A new line was thus obtained in which the preponderant effect of the values at high concentrations of inulin was eliminated. Its intercept with the UV axis and the standard error of the intercept were also calculated. These are presented in the right-hand columns of Table III. The new line can be used for obtaining new weighting coefficients and the data recalculated. This was tried in several instances, but since this resulted in no further appreciable change in the intercept or its standard error, further approximations were abandoned and only the results of the first weighting are presented.

In the evaluation of clearance as a function of plasma concentration, any systematic trend should appear as a significant slope of the regression line. Since in this case UV is divided by $P$, the effect of those errors which are proportional to concentration is cancelled out and no weighting is necessary.

\section{RESULTS}

The details of two representative experiments appear in Table I. In the first experiment (subject $O$. C.) the inulin clearance varied about a mean value of $98.3 \mathrm{ml} . / \mathrm{min}$. by from +7.2 to -6.0 per cent and there was no obvious tendency for a systematic change in clearance as the plasma concentration of inulin varied between 6 and $180 \mathrm{mg}$. per cent. In the second experiment (subject J. B.), the clearance varied between +10.8 and -6.5 per cent of the mean value of $129.4 \mathrm{ml} . / \mathrm{min}$. and the clearance seems to be somewhat higher at high plasma concentrations. On statistical analysis, this trend is more nearly significant than in any other experiment, but could be expected by chance alone in from 5 to 10 per cent of cases.

Table II presents a summary of all experiments. Here the average clearance at each approximately constant plasma level of inulin is presented. With one exception (subject A. G.) the clearance is almost identical at all plasma concentrations for each subject.

The statistical data on all subjects appear in Tables III and IV. In Table III are presented the intercepts and the standard errors of the intercepts of the regression line of excretion rate on plasma concentration of inulin. Data derived from calculations before and after weighting are

TABLE II

Inulin clearance at a series of plasma concentrations of inulin. Data is average of 3 consecutive periods except where noted

\begin{tabular}{|c|c|c|c|c|c|c|c|c|c|}
\hline \multirow[b]{2}{*}{ Patient } & \multirow[b]{2}{*}{ Age } & \multirow[b]{2}{*}{ S. A. } & \multicolumn{2}{|c|}{ Average inulin } & \multirow[b]{2}{*}{ Patient } & \multirow[b]{2}{*}{ Age } & \multirow[b]{2}{*}{ S. A. } & \multicolumn{2}{|c|}{ Average inulin } \\
\hline & & & Plasma & Clearance & & & & Plasma & Clearance \\
\hline J. B. & 25 & $\begin{array}{l}s q . m . \\
1.65\end{array}$ & $\begin{array}{r}m g . \% \\
4.4 \\
47.3 \\
108.9\end{array}$ & $\begin{array}{c}\text { ml./min. } \\
124 \\
132 \\
133\end{array}$ & E. L. & 22 & $\begin{array}{c}s q . m . \\
1.60\end{array}$ & $\begin{array}{r}m g . \% \\
4.3 \\
49.4 \\
169.7\end{array}$ & $\begin{array}{c}\text { ml. } / \min . \\
99 \\
108 \\
104\end{array}$ \\
\hline V. C. & 35 & 1.67 & $\begin{array}{r}5.9 \\
63.9 \\
173.2\end{array}$ & $\begin{array}{l}105 \\
105 \\
104\end{array}$ & J. M. & 30 & 1.62 & $\begin{array}{r}8.9 \\
54.7 \\
127.9\end{array}$ & $\begin{array}{l}117 \\
115 \\
111\end{array}$ \\
\hline O. C. & 38 & 1.62 & $\begin{array}{c}5.7 \\
60.0 \dagger \\
176.3\end{array}$ & $\begin{array}{l}99 \\
99 \dagger \\
97\end{array}$ & L. P. & 26 & 1.37 & $\begin{array}{r}8.1 \\
42.3 \\
124.3\end{array}$ & $\begin{array}{r}99 \\
101 \\
100\end{array}$ \\
\hline A. G. & 26 & 1.49 & $\begin{array}{r}9.4 \\
52.9 \\
138.6\end{array}$ & $\begin{array}{l}129 \\
124 \\
108\end{array}$ & L. R. & 28 & 1.60 & $\begin{array}{r}5.6 \\
55.7 \\
177.3\end{array}$ & $\begin{array}{l}111 \\
117 \\
119\end{array}$ \\
\hline E. H. & 23 & 1.34 & $\begin{array}{r}4.4 \\
35.5 \\
123.7\end{array}$ & $\begin{array}{l}78 \\
84 \\
86\end{array}$ & J. W. & 31 & 1.48 & $\begin{array}{r}3.2 \\
37.2 \\
101.2\end{array}$ & $\begin{array}{l}146 \\
145 \\
153\end{array}$ \\
\hline J. H.* & 34 & 1.73 & $\begin{array}{r}10.3 \\
55.2 \\
151.6\end{array}$ & $\begin{array}{l}99 \\
99 \\
99\end{array}$ & E. W. & 29 & & $\begin{array}{r}6.0 \\
63.3 \\
179.2\end{array}$ & $\begin{array}{l}92 \\
97 \\
90\end{array}$ \\
\hline M. J. & 33 & 1.60 & $\begin{array}{r}13.6 \\
154.9\end{array}$ & $\begin{array}{l}69 \\
63\end{array}$ & G. W. & 27 & 1.56 & $\begin{array}{r}4.0 \\
46.4 \\
138.4\end{array}$ & $\begin{array}{l}119 \\
109 \\
117\end{array}$ \\
\hline
\end{tabular}


TABLE III

Statistical analysis of regression of rate of excretion on plasma concentration of inulin before and after weighting

\begin{tabular}{|c|c|c|c|c|c|c|}
\hline Patient & Intercept & $\begin{array}{l}\text { ghted serie } \\
\text { Standard } \\
\text { error of } \\
\text { intercept }\end{array}$ & " $t " *$ & Intercept & $\begin{array}{l}\text { hted series } \\
\text { Standard } \\
\text { error of } \\
\text { intercept }\end{array}$ & " $t$ "** \\
\hline $\begin{array}{l}\text { J. B. } \\
\text { V. C. } \\
\text { O. C. } \\
\text { A. G. } \\
\text { E. H. } \\
\text { J. H. } \\
\text { M. J.† } \\
\text { E. L. } \\
\text { J. M. } \\
\text { L. P. } \\
\text { L. R. } \\
\text { J. W. } \\
\text { E. W. } \\
\text { G. W. }\end{array}$ & $\begin{array}{r}\text { mg./min. } \\
-0.484 \\
+0.278 \\
+0.734 \\
+5.160 \\
+0.057 \\
-0.151 \\
+1.259 \\
-0.172 \\
+1.618 \\
-0.077 \\
-0.625 \\
-2.100 \\
+2.900 \\
-1.250\end{array}$ & $\begin{array}{c}\text { mg./min. } \\
2.54 \\
3.42 \\
1.81 \\
7.69 \\
4.72 \\
2.10 \\
3.47 \\
6.55 \\
4.80 \\
1.01 \\
0.78 \\
24.55 \\
3.21 \\
2.38\end{array}$ & $\begin{array}{l}0.19 \\
0.08 \\
0.40 \\
0.67 \\
0.01 \\
0.07 \\
0.36 \\
0.03 \\
0.34 \\
0.08 \\
0.80 \\
0.09 \\
0.90 \\
0.53\end{array}$ & $\begin{array}{l}\text { mg. } / \min . \\
-0.386 \\
+0.127 \\
+0.053 \\
+1.654 \\
+0.270 \\
+0.060 \\
+0.985 \\
+0.314 \\
+0.245 \\
+0.145 \\
-0.419 \\
-0.097 \\
+0.163 \\
+0.284\end{array}$ & $\begin{array}{c}\text { mg./min. } \\
0.19 \\
0.50 \\
0.26 \\
1.32 \\
0.36 \\
0.70 \\
0.53 \\
0.34 \\
0.87 \\
0.28 \\
0.39 \\
0.49 \\
0.65 \\
0.16\end{array}$ & $\begin{array}{l}2.03 \\
0.25 \\
0.20 \\
1.25 \\
0.75 \\
0.09 \\
1.86 \\
0.92 \\
0.28 \\
0.52 \\
1.07 \\
0.20 \\
0.25 \\
1.78\end{array}$ \\
\hline
\end{tabular}

* For all but noted exceptions, there are 7 degrees of freedom (nine clearance periods). For $p$ to be $<0.05$, " $t$ " must exceed 2.3 ; for it to be $<0.01$, " $t$ " must exceed 3.5.

† 6 degrees of freedom. For $p$ to be $<0.05$, " $t$ " must exceed 2.4 .

$\ddagger 4$ degrees of freedom. For $p$ to be $<0.05$, " $t$ " must exceed 2.7.

included. In the unweighted series, the intercepts are small-less than $2.0 \mathrm{mg}$. per min. in 11 of 14 subjects-as frequently positive as negative, and never significantly different from zero. However, it is apparent that this analysis is, as predicted in the discussion of methods, biased. The intercepts have, relative to their own values, high standard errors, so that the probabilities, instead of being

TABLE IV

Statistical analysis of regression of clearance on plasma concentration of inulin

\begin{tabular}{lccc}
\hline \hline Patient & Slope & $\begin{array}{c}\text { Standard error } \\
\text { of slope }\end{array}$ & "t"* \\
\hline J. B. & +0.075 & 0.05 & 1.50 \\
V. C. & -0.008 & 0.02 & 0.40 \\
O. C. $\dagger$ & -0.016 & 0.02 & 0.80 \\
A. G. & -0.165 & 0.23 & 0.72 \\
E. H. & +0.040 & 0.07 & 0.57 \\
J.H. & +0.000 & 0.02 & 0.00 \\
M. J. & +0.134 & 0.20 & 0.67 \\
E. L. & +0.002 & 0.05 & 0.04 \\
J. M. & -0.055 & 0.79 & 0.70 \\
L. P. & +0.006 & 0.10 & 0.06 \\
L. R. & +0.019 & 0.05 & 0.38 \\
J. W. & +0.090 & 0.16 & 0.56 \\
E. W. & -0.035 & 0.03 & 1.17 \\
G. W. & -0.005 & 0.04 & 0.13 \\
\hline
\end{tabular}

* Same significance as in Table III.

t Same significance as in Table III.

‡ Same significance as in Table III. randomly distributed from high values to near significance, are all large. After weighting, the intercepts generally approach zero more closely, and only one is greater than $1.0 \mathrm{mg} . / \mathrm{min}$. The standard errors of the intercepts are reduced to a proportionately greater degree. None of the intercepts differ significantly from zero. The probabilities are more reasonably distributed in the weighted than in the unweighted series. In Table IV are presented the slopes and the standard errors of the slopes of the regression lines of clearance on plasma concentration of inulin. The slopes are positive in eight instances, negative in six, and small in all. None differs significantly from zero. The series of probabilities seem to be reasonably well distributed.

\section{DISCUSSION}

Clearance measurements are subject to a certain amount of essentially inherent error. Smith (5) analyzed data from a large number of experiments of variable duration in which inulin clearance was measured by the constant infusion technique and in which no systematic trend in the clearance was evident. $\mathrm{He}$ found that the standard deviation about the mean clearance for an individual was 8.9 per cent, so that about 70 per cent of the periods should be within \pm 8.9 per cent of the average of all periods and 96 per cent within \pm 17.8 per cent of the average. He concluded that variability of this magnitude is to be expected in the routine measurement of inulin clearance. In the experiments presented in Table I, as well as in all the other experiments, the observed variability was within these limits. Most of this variability can be attributed to incomplete emptying of the bladder and to the accumulation in or washing out from the dead space of inulin as a result of an increase or decrease in urine flow. Errors due to incomplete emptying are not cumulative, but tend to cancel out in successive periods. The residual from one period is usually collected in the following period, so that the average of the two is more nearly correct. Dead space errors are likely to be acute, and if inulin is lost into or appears from dead space as a result of a change in urine flow, a steady state is soon reached. Accordingly, the average of successive periods is likely to reflect this error less than the single period in which the acute 
change occurred. In fact, it may be seen from Table III that when the average of three successive periods at one plasma level of inulin is compared to the average of all (usually nine) periods for any individual, the variability is much smaller than that estimated by Smith and by others (3).

With these considerations in mind, it seems likely that the variability observed was well within the limits of error of the technique employed. It is still possible that actual fluctuations in filtration rate account for part of the variability. The data offer no evidence to support the contention that inulin clearance is dependent upon inulin plasma concentration. All of this evidence is in harmony with the conclusions drawn by Shannon and Smith (1) and by Miller, Alving, and Rubin (2).

While it is not possible to offer a definitive explanation for the differences between these observations and those of Ferguson and her associates (3), some comment and speculation seem to be in order. These authors reported a series of inulin clearance measurements following a single intravenous injection of the test substance and another series of clearance measurements at several constant plasma concentrations of inulin. The variation of clearance with plasma level of inulin is not as impressive in the second series as in the first. When subjected to the types of analysis used in this report, the results are as follows: Before weighting the intercepts calculated for each experiment did not differ significantly from zero, but when the two experiments on C. M. were treated as one, the difference between the intercept and zero was of borderline significance ( $p=$ $0.01-0.05)$; after weighting, the difference between the intercept and zero for both individual and the combined experiment on $C$. M. were of borderline significance, whereas this difference was not significant in the experiments on W. R. and J. C.

The first series of experiments in which the plasma inulin concentration was falling rapidly showed a remarkable dependence of clearance on plasma concentration, the ratio of highest to lowest clearance averaging 1.4 and reaching 2.3 in one subject. The greatest source of error in this type of experiment is the uncertainty of the correction for delay time. Recent evidence (6-8) suggests that a delay time correction of from 20 to 30 minutes may be more nearly correct than the $2 \frac{1}{2}$ to
6 minutes correction used by these authors. Considering the form of the curve relating plasma concentration of inulin to time after a single intravenous injection, it may be deduced that a longer delay time correction would reduce the apparent clearance at high plasma inulin levels much more than at low levels, and so reduce the dependence which they emphasize. This surmise is supported if their subjects are divided for purposes of analysis into two groups, one of 8 whose initial inulin clearance exceeds $80 \mathrm{ml} . / \mathrm{min}$., the other of 7 whose initial clearance is less than $80 \mathrm{ml} . / \mathrm{min}$. Necessarily, the plasma concentration of inulin fell less rapidly in those with lower clearances. The values of the intercepts decrease with inulin clearance and the mean intercept of the first group is significantly smaller than that of the second. In other words, Ferguson's results are most striking when the delay time error is probably largest, and least striking when the error is predictably smallest.

Systematic errors possibly inherent in both series of their experiments such as those due to chemcal methodology, to variable plasma and urine inulinoid blanks, to systematic changes in urine flow with consequent systematic dead space errors, and to inhomogeneous inulin are all impossible to evaluate in the report of Ferguson. As far as can be determined, none of these errors were important in the data herein reported.

The fact that the experiments performed by these authors at constant plasma concentrations of inulin show a dependence of clearance on plasma concentration that is at best of borderline significance, and the recognition that serious reservations must be entertained in the case of their single injection experiments, tend to reduce the area of disagreement between their data and that presented in this paper.

\section{SUMMARY}

1. The clearance of inulin has been studied in 14 normal subjects in experiments in which the concentration of inulin in plasma was held constant for 3 periods at each of three levels, about 5 , 50 and $175 \mathrm{mg}$. per cent, respectively.

2. Analysis of the data indicated that within the limits of error of the method, the clearance was identical at all plasma concentrations.

3. These data support the conclusion that inulin is cleared at the level of glomerular filtration. 


\section{ACKNOWLEDGMENT}

We are greatly indebted to Dr. Max Halperin, of the Biometrics Section of the National Heart Institute, for his valuable advice and assistance on the statistical methods and computations used in this paper.

\section{REFERENCES}

1. Shannon, J. A., and Smith, H. W., The excretion of inulin, xylose and urea by normal and phlorizinized man. J. Clin. Invest., 1935, 14, 393.

2. Miller, B. F., Alving, A. S., and Rubin, J., The renal excretion of inulin at low plasma concentrations of this compound, and its relationship to the glomerular filtration rate in normal, nephritic and hypertensive individuals. J. Clin. Invest., 1940, 19, 89.

3. Ferguson, M. H., Olbrich, O., Robson, J. S., and Stewart, C. P., The use of inulin clearance as a meas- ure of glomerular filtration. Quart. J. Exper. Physiol., 1950, 35, 251.

4. Harrison, $\mathrm{H}$. A., A modification of the diphenylamine method for determination of inulin. Proc. Soc. Exper. Biol. \& Med., 1942, 49, 111.

5. Smith, H. W., Goldring, W., and Chasis, H., The measurement of the tubular excretory mass, effective blood flow and filtration rate in the normal human kidney. J. Clin. Invest., 1938, 17, 263.

6. Michie, A. J., and Michie, C. R., Attainment of equilibrium between plasma and urine with reference to measurement of renal clearances. J. Urol., 1951, 66, 518 .

7. Morales, P. A., Crowder, C. H., Fishman, A. P., Maxwell, M. H., and Gomez, D. M., Measurement and significance of urinary appearance time in the dog. Am. J. Physiol., 1950, 163, 454.

8. Bradley, S. E., Nickel, J. F., and Leifer, E., The distribution of nephron function in man. Trans. Assoc. Am. Phys. (In press). 